\title{
Control of Feedforward Dendritic Inhibition by NMDA Receptor- Dependent Spike Timing in Hippocampal Interneurons
}

\author{
Gianmaria Maccaferri and Raymond Dingledine \\ Department of Pharmacology, Emory University School of Medicine, Atlanta, Georgia 30322
}

Two putative functional populations of feedforward interneurons with distinct spike-timing properties were identified in stratum radiatum of the CA1 rat hippocampus. Interneurons with fast (half width, $<100 \mathrm{msec}$ ) EPSPs fired after short EPSPspike latencies and with a high degree of temporal precision compared with cells with slow (half width, $>100 \mathrm{msec}$ ) EPSPs. Spike timing in fast and slow interneurons occurred at different phases of the EPSPs of simultaneously activated pyramidal cells. In addition, firing of fast interneurons preceded action potentials in principal neurons, whereas action potentials in slow interneurons could either precede or follow firing in pyramidal cells. Temporal integration of separate inputs leading to synaptically evoked firing was more prominent in slow than fast interneurons. Functional diversity between the two putative populations was abolished by the NMDA receptor (NMDAR) antagonist D-(-)-2-amino-5-phosphonopentanoic acid (D-AP-5).
The axon of both cell types was primarily restricted to striatum radiatum or to striatum lacunosum-moleculare in the case of slow cells, suggesting targeting of principal cell dendrites for the majority of the cells of this study. Indeed, firing of slow and fast interneurons generated similar unitary IPSCs (uIPSCs) in pyramidal neurons. uIPSCs were mediated by GABA $_{A}$ receptors and had in most cases small amplitudes and slow kinetics. Our results suggest that functionally heterogeneous interneurons encode the temporal properties of dendritic feedforward inhibition, and that NMDARs play an essential role in shaping the integrative properties of interneurons and in setting the timing of GABA release.

Key words: NMDA receptor; interneuron; spike timing; inhibition; feedforward; GABA $A_{A}$ receptor; kinetics; EPSP; dendrite; axon
Feedforward inhibition is a common feature of cortical circuits and results from the parallel activation of GABAergic interneurons and principal cells by the same excitatory input (Buzsaki, 1984). For example, stimulation of the Schaffer collaterals in the hippocampus produces a biphasic EPSP/IPSP sequence on CA1 pyramidal neurons (Schwartzkroin, 1975), which is the result of monosynaptic release of glutamate and disynaptic release of GABA (Knowles and Schwarzkroin, 1981; Miles and Wong, 1984; Miles, 1990; Sayer et al., 1990; Pouille and Scanziani, 2001). Feedforward GABAergic input can suppress action potential firing and backpropagation (Alger and Nicoll, 1982; Tsubokawa and Ross, 1996), regulate synaptic plasticity (Davies et al., 1991; Mott and Lewis, 1991), or enforce the temporal fidelity of action potentials (Pouille and Scanziani, 2001). To ensure the effective timing of GABA release on principal neurons, activation of interneurons needs to occur within appropriate temporal windows. Therefore, the specific properties of how EPSPs are converted into spikes (EPSP-spike coupling) in interneurons can impact feedforward network mechanisms (Fricker and Miles, 2000).

EPSP-spike coupling in central neurons is variable and depends in part on the EPSP kinetics of the examined cell type (Fricker

\footnotetext{
Received Feb. 20, 2002; revised March 28, 2002; accepted April 22, 2002.

This work was supported by a National Alliance for Research on Schizophrenia and Depression young investigator award (G.M.), by the National Institute of Mental Health (G.M.), and by the National Institutes of Health (R.D.). We thank Dr. J. Dempster (University of Strathclyde, Glasgow, UK) for providing us with the Whole Cell Program analysis package.

Correspondence should be addressed to Gianmaria Maccaferri, Department of Physiology, Northwestern University Medical School, 303 East Chicago Avenue, Chicago, IL 60611. E-mail: g-maccaferri@northwestern.edu.

Copyright (C) 2002 Society for Neuroscience $0270-6474 / 02 / 225462-11 \$ 15.00 / 0$
}

and Miles, 2000). At one extreme, some connections are built to ensure the precise generation of action potentials after every single EPSP, thus providing a faithful representation of presynaptic timing to the postsynaptic cell (Zhang and Trussel, 1994; Borst et al., 1995; Brew and Forsythe, 1995; Koyano et al., 1996). In the majority of cases, however, action potentials result from the summation of subthreshold EPSPs after coincidence detection or integration of synaptic input (Shadlen and Newsome, 1994; Konig et al., 1996; Reyes et al., 1996; Geiger et al., 1997; Koch and Segev, 2000). Direct studies of EPSP-spike coupling in neocortical and hippocampal fast-spiking (Geiger et al., 1997; Galarreta and Hestrin, 2001) or otherwise unidentified hippocampal interneurons (Miles, 1990; Fricker and Miles, 2000) have revealed fast EPSP kinetics, short EPSP-spike latencies, and a high degree of temporal precision when compared with principal cells. However, despite evidence for short EPSP-spike latency in interneurons (Miles, 1990; Csicsivari et al., 1998; Fricker and Miles, 2000), feedforward $\mathrm{GABA}_{\mathrm{A}}$-mediated IPSPs can occur after much longer delays on the postsynaptic target cells (McLean et al., 1995), suggesting the existence of interneurons with long latency EPSP-spike coupling, yet uncharacterized. This indicates that the study of the mechanisms involved in GABAergic feedforward circuits may be complicated by anatomical diversity of the interneuronal population (Freund and Buzsaki, 1996; Somogyi et al., 1998; McBain and Fisahn, 2001).

Here, we address directly EPSP-spike coupling, synaptic integration, and the functional properties of postsynaptic targeting in two putative functional populations of stratum radiatum interneurons. Our results reveal a high degree of functional diversity between the two populations in spike timing and integration, which is determined by the activation of NMDA receptors 
(NMDARs) in interneurons. As a consequence, the temporal specificity of GABAergic feedforward mechanisms can be dynamically encoded by functionally distinct types of interneurons and can selectively impact specific phases of synaptic activity in principal neurons.

\section{MATERIALS AND METHODS}

Slice preparation. The procedure used to obtain slices is similar to the one described by Maccaferri and McBain (1996). Briefly, young rats (Sprague Dawley, postnatal day 12-16) were deeply anesthetized using isoflurane and killed by decapitation, in accordance with National Institutes of Health and Institutional protocols. The brain was quickly removed and placed into ice-cold "cutting solution" of the following composition (in mM): $130 \mathrm{NaCl}, 24 \mathrm{NaHCO}_{3}, 3.5 \mathrm{KCl}, 1.25 \mathrm{NaH}_{2} \mathrm{PO}_{4}, 1 \mathrm{CaCl}_{2}, 3$ $\mathrm{MgSO}_{4}$, and 10 glucose, saturated with $95 \% \mathrm{O}_{2}, 5 \% \mathrm{CO}_{2}$, at $\mathrm{pH}$ 7.4. The hemisected brain was then glued onto the stage of a vibrating microtome (Leica, Nussloch, Germany) and sections of $300 \mu \mathrm{m}$ thickness were cut and stored in an incubation chamber for $\sim 1 \mathrm{hr}$ at room temperature before use. The composition of the artificial CSF (ACSF) in the incubation and recording chamber was (in $\mathrm{mM}$ ): $130 \mathrm{NaCl}, 24 \mathrm{NaHCO}_{3}, 3.5$ $\mathrm{KCl}, 1.25 \mathrm{NaH}_{2} \mathrm{PO}_{4}, 3 \mathrm{CaCl}_{2}, 1.5 \mathrm{MgSO}_{4}$, and 10 glucose, saturated with $95 \% \mathrm{O}_{2}, 5 \% \mathrm{CO}_{2}$, at $\mathrm{pH}$ 7.4. Slices were then transferred, as needed, to the recording chamber and observed under an upright Zeiss Axioskop microscope (Zeiss, Oberkochen, Germany) equipped with a $40 \times$ water immersion differential interference contrast objective coupled to an infrared camera system (Hamamatsu, Tokyo, Japan). Interneurons were located in the CA1 stratum radiatum or at the border between stratum radiatum and stratum lacunosum-moleculare and usually, but not always, had a multipolar appearance with fine dendritic processes. The firing pattern was routinely observed before starting the recording to confirm the nonpyramidal nature of the target cell.

Electrophysiological recordings. Conventional whole-cell current-clamp and voltage-clamp techniques were applied using two Axopatch-1D amplifiers (Axon Instruments, Union City, CA). Pipettes used for currentclamp experiments (resistance, $\sim 5 \mathrm{M} \Omega$ ) were filled with the following solution (in mM): $120 \mathrm{~K}$-gluconate, $4 \mathrm{NaCl}, 4 \mathrm{MgATP}, 0.3 \mathrm{GTP}, 10$ HEPES, and $0.5 \%$ biocytin to a $\mathrm{pH}$ of 7.2 and $285-295$ mOsm. Voltageclamp recordings were performed on pyramidal cells with electrodes of $\sim 3 \mathrm{M} \Omega$ resistance and filled with a solution of a different composition to minimize voltage-dependent conductances. The filling solution was (in mM): $120 \mathrm{CsCl}, 4 \mathrm{MgATP}, 0.3 \mathrm{GTP}, 5 \mathrm{~N}$-(2,6-dimethylphenylcarbamoylmethyl)trethylamnionium bromide, $10 \mathrm{HEPES}$, and $0.5 \%$ biocytin to a $\mathrm{pH}$ of 7.2-7.3 and 285-295 mOsm. Series resistance was $\sim 15 \mathrm{M} \Omega$ and was corrected by $\sim 50-60 \%$. All current-clamp recordings of EPSPs were performed at room temperature $\left(\sim 24^{\circ} \mathrm{C}\right)$ in ACSF as described above with the addition of $20 \mu \mathrm{M}$ bicuculline. Double recordings from synaptically connected interneuron $\rightarrow$ pyramidal cell pairs were performed at $\sim 30^{\circ} \mathrm{C}$ in the absence of bicuculline to allow comparison with the data reported by Maccaferri et al. (2000). The temperature of the solution was monitored by a probe in the recording chamber and could be changed by a heating system applied to the perfusing solution before entering the bath (TC344A; Warner Instruments, Hamden, CT). Membrane potentials recorded in current clamp have been corrected for a junction potential between intracellular and extracellular solution, which was experimentally measured to be $10 \mathrm{mV}$ (Neher, 1992).

Evoked EPSPs. EPSPs were evoked by monopolar platinum/iridium glass-coated electrodes (Frederick Haer, Bowdoinham, ME) connected to a constant-current isolation unit (World Precision Instruments, Sarasota, FL). Pulses of 5-100 $\mu \mathrm{A}$ amplitude and 250-300 $\mu$ sec duration were used to stimulate excitatory afferents in stratum radiatum, stratum lacunosum-moleculare, or at the border between the two layers.

Interneurons were maintained around their resting potential. Small variations of the membrane potential attributable to spontaneous activity were monitored and, when necessary, compensated by DC injection. A small hyperpolarizing current step (5-20 pA amplitude; 50 msec duration) was used to monitor and correct the bridge balance. All analyses were performed on averaged EPSPs from $\sim 20-60$ sweeps.

Paired recordings. Paired recordings from synaptically connected interneuron $\rightarrow$ pyramidal cell pairs (see Fig. 5) were performed using a two-step procedure. First, uIPSCs were evoked in the postsynaptic pyramidal cell (held in voltage-clamp at $-70 \mathrm{mV}$ ) by action potentials triggered in the presynaptic interneuron (held in current clamp) by short current pulses. This part of the protocol was performed in ACSF at $\sim 30^{\circ} \mathrm{C}$. In the second part of the experiment, bicuculline $(20 \mu \mathrm{M})$ was bath perfused and the temperature was reduced to $24^{\circ} \mathrm{C}$. EPSPs were recorded from the same interneuron as described above. Double recordings from unconnected neurons (see Fig. 7) were performed in the presence of bicuculline and at $24^{\circ} \mathrm{C}$.

Data analysis. Data were filtered at $5 \mathrm{kHz}$ and digitized at $20 \mathrm{kHz}$ using a Digidata 1200 (Axon Instruments) analog-to-digital board. Analysis was performed using pClamp (Axon Instruments), Origin (MicroCal, Northampton, MA), Excel (Microsoft, Seattle, WA), Whole Cell Program (courtesy of Dr. J. Dempster, University of Strathclyde, Glasgow, UK), and Prism software (GraphPad, San Diego, CA) packages. Analysis of the uIPSCs was performed as described by Maccaferri et al. (2000) by spike-triggered alignment of single sweep IPSCs. Recordings were carefully selected after visual inspection of individual traces to discard records in which spontaneous IPSCs obscured evoked responses. All measurements were performed on averaged uIPSCs (usually $\sim 30-60$ traces) recorded from the different connections. The decay time constant of the UIPSC was fitted by a monoexponential function.

Statistical comparisons were performed using the appropriate Student's $t$ test. A two-way ANOVA with Bonferroni post hoc test to compare replicate means by row was performed for the analysis of the data presented in Figure 4. Values are given as mean \pm SE.

Statistical analysis of frequency distributions and evaluation of the best fit. We analyzed the distribution of the EPSP half width (Fig. $1 G$ ) by fitting the calculated frequency histogram with different models using GraphPad Prism software (Motulsky, 1999). Comparisons between different hierarchical models were quantified by an $F$ test as, for example, in the case of a single Gaussian versus the sum of two Gaussians. The equation used for a single Gaussian was $\left.y=A \times \exp \left\{-0.5 \times\left[x-x_{\mathrm{c}}\right) / w\right]^{2}\right\}$, where $A$ represents the amplitude of the peak, $x_{\mathrm{c}}$ represents the mean, and $w$ represents the SD. The $F$ value can be used to quantify the improvement in fit achieved by a more complex model compared with a simpler one. The $F$ value is calculated as the relative increase in the sum of squares (SS) divided by the relative increase in degrees of freedom, going from the more complicated to the simpler model (Horn, 1987; Motulsky, 1999). If the simpler model results in a significantly better fit, the expectation is that the relative increase in the SS equals the relative increase in degrees of freedom $(F \sim 1)$. Alternatively, if the more complicated model provides a significantly better fit, the relative increase in the SS is expected to be greater than the relative increase in degrees of freedom $(F>1)$. A probability value can then be extracted from the resulting $F$ value and the associated degrees of freedom, which indicates whether the simpler model might by chance cause the same improvement in the fit with another valid set of data. If that probability is sufficiently low, we adopt the more complex model. When comparing nonhierarchical models, for example a sum of two Gaussians versus a log Gaussian $\left[y=A \times \exp \left\{-0.5 \times\left[\ln \left(x-x_{\mathrm{c}}\right) / w\right]^{2}\right\}\right]$ to account for the asymmetry of the distribution, we used three parameters as indicators of the goodness of the fit: (1) the SS of the nonlinear fit, (2) the SD of the vertical distance of the points from the line $\left(\mathrm{S}_{\mathrm{y}, \mathrm{x}}\right)$, and (3) the nonlinear regression coefficient $R^{2}$ (Motulsky, 1999). No good fit could be achieved by a single, nonhierarchical model, which we interpreted as evidence for the presence of multiple populations. Models were rejected if best-fit parameters did not make scientific sense (for example, a negative Gaussian amplitude) (Motulsky, 1999).

All of these objective criteria of evaluation were in full agreement with the visual impression of the fits.

Quantification of the overlap of the fitted distributions and of the errors associated with the 100 msec threshold. We quantified errors associated with a cutoff of $100 \mathrm{msec}$ to discriminate between slow and fast interneurons. Evaluation was based on the ratio between areas delimited by the probability density function derived from the sum of the two Gaussians, each individual Gaussian component, and the $100 \mathrm{msec}$ threshold (Fig. $1 E$ ). Areas were integrated using Clampfit of the pClamp program suite after having imported the fitted curves. For example, we estimated the fraction of cells misassigned to the fast population as the ratio between the area of the slow Gaussian in the $0-100$ msec interval and the probability density function derived from the sum of the two Gaussians in the same interval $[0.078 /(0.078+0.405)=0.16]$. With a similar procedure, we calculated that $15 \%$ of the area under the slow Gaussian falls in bins $<100 \mathrm{msec}$. The fractional area delinited by the fast Gaussian component in the interval of $100-600 \mathrm{msec}$ was negligible $(<0.001)$.

In conclusion, the half width $<100 \mathrm{msec}$ criterion is associated with an $84 \%$ probability of correctly defining cells belonging to the fast population and a $<1 \%$ probability of missing any, whereas the half width $>100$ 

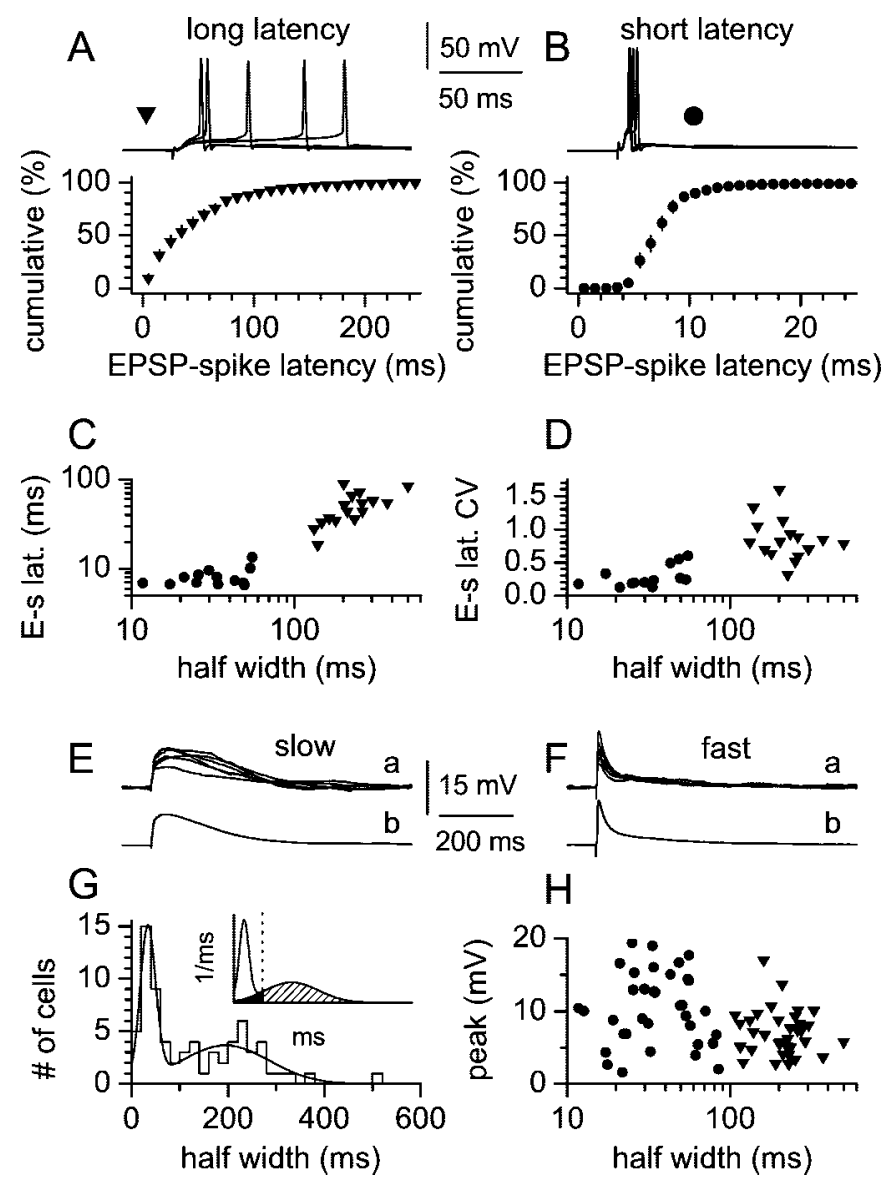

Figure 1. EPSP-spike coupling in interneurons. $A, B$, Cumulative distribution of EPSP-spike latencies for long-latency ( $A$, filled triangles) and short-latency ( $B$, filled circles) interneurons at a $P_{\mathrm{f}}$ of $\sim 0.5$. The insets above the plots show five sweeps for either cell type. Data are the mean \pm SE of the individual distributions for 16 slow $(A)$ and 14 fast $(B)$ interneurons. $C$, Plot of EPSP-spike latencies ( $E$-s lat.) versus EPSP half width. Notice the longer values associated with slower cells compared with faster interneurons. $D$, Summary graph showing the CV of spike latencies $(E-s$ lat. $C V)$ as a function of EPSP half width. Notice that slower interneurons are associated with more dispersed distributions compared with faster cells. $E, F$, Subthreshold responses from the same cells as in $A$ and $B$. $G$, Distribution of EPSP half width in 70 stratum radiatum interneurons and fit by a sum of two Gaussian functions $[y=$ $A 1 \times \exp \left\{-0.5 \times\left[\left(x-x 1_{\mathrm{c}}\right) / w 1\right]^{2}\right\}+A 2 \times \exp \left\{-0.5 \times\left[\left(x-x 2_{\mathrm{c}}\right) / w 2\right]^{2}\right\}$. The values of the parameters obtained by the fit were: $\mathrm{A} 1=14.37, \mathrm{x}_{\mathrm{c}}=$ $33.7, \mathrm{w} 1=15.92, \mathrm{~A} 2=3.691, \mathrm{x} 2 \mathrm{c}=194.6, \mathrm{w} 2=90.6, R^{2}=0.91$. The inset shows the areas delimited by the derived probability density function, the $100 \mathrm{msec}$ threshold (dotted line), and the slow Gaussian component of the probability density function. The area belonging to the fast Gaussian in the interval of $>100 \mathrm{msec}$ was negligible. The probability values for the different areas were: white area, 0.405; black area, 0.078; striped area, 0.517 . The $x$-axis is shown in the $0-600 \mathrm{msec}$ interval. $H$, EPSP kinetics as a function of EPSP amplitude: notice the similar size of fast (filled circles) and slow (filled triangles) EPSPs and the lack of correlation.

msec criterion will identify with virtual certainty only cells belonging to the slow distribution but will miss $\sim 15 \%$ of slow cells.

Visualization of recorded cells and reconstruction. Methods were similar to those of Maccaferri and McBain (1996). Briefly, slices were fixed for $1-10 \mathrm{~d}$ in a $4 \%$ paraformaldehyde PBS solution at $4^{\circ} \mathrm{C}$. Endogenous peroxidase activity was removed by incubating the slices in $10 \%$ methanol, $1 \% \mathrm{H}_{2} \mathrm{O}_{2}$ PBS solution. Biocytin staining was processed using an avidin-HRP reaction (Vectastain avidin-biotin complex Elite Kit; Vector Laboratories, Burlingame, $\mathrm{CA}$ ), and axon visualization was improved using a PBS solution containing $\mathrm{NiNH}_{4} \mathrm{SO}_{4}(1 \%)$ and $\mathrm{CoCl}_{2}(1 \%)$. Slices were not resectioned, but were directly mounted on the slide using an aqueous mounting medium (Vectashield; Vector Laboratories). Alternatively, they were first dehydrated and then mounted on the slide using a toluene solution (Permount; Fisher Scientific, Fair Lawn, NJ). Slices were observed at $100 \times$ magnification and reconstructed using a camera lucida.

\section{RESULTS EPSP-spike coupling in stratum radiatum slow and
fast interneurons}

After blockade of fast inhibitory transmission by bicuculline (20 $\mu \mathrm{M}$ ), we studied action potential generation in CA1 stratum radiatum interneurons after stimulation of excitatory afferents. Cells were recorded under whole-cell, current-clamp conditions. Interneurons were kept close $( \pm 2 \mathrm{mV})$ to their resting potential. Cells displaying spontaneous activity were hyperpolarized and cells with more hyperpolarized membrane potentials were depolarized to maintain comparisons at similar membrane voltages (approximately $-63 \mathrm{mV}$ ). Stimulation intensity was set at $\sim 0.5$ firing probability $\left(P_{\mathrm{f}}\right)$ so that both suprathreshold and subthreshold responses from the same neuron could be analyzed. As shown in Figure $1 A, B$, two functionally distinct groups of cells could be easily distinguished. In the first group (Fig. $1 A$ ), action potentials were generated after a long latency (mean value $>15 \mathrm{msec}$ ) from the onset of the EPSP. From 16 recordings, the mean EPSP-spike latency was $50.4 \pm 5.0 \mathrm{msec}$ (mean $\pm \mathrm{SE}$ ). In addition, in this group of cells, precision of spike timing was not faithfully maintained, as reflected by the large coefficient of variation $(\mathrm{CV}=$ $\mathrm{SD} /$ mean) of the distributions of the EPSP-spike latencies calculated for each individual neuron (mean $\mathrm{CV}$ was $0.85 \pm 0.07 ; n=$ 16). On the contrary, suprathreshold responses in the second group of cells (Fig. 1B) generated shorter EPSP-spike latencies [mean value was $<15 \mathrm{msec}(8.0 \pm 0.5 \mathrm{msec} ; n=14)$ ] and spike-timing precision was much tighter, as indicated by the $\mathrm{CV}$ of each distribution (mean value was $0.27 \pm 0.04 \mathrm{msec} ; n=14$ ). No differences were found either in the membrane potential $[-63.1 \pm 0.7 \mathrm{mV}(n=16) \mathrm{vs}-62.9 \pm 0.6 \mathrm{mV}(n=14) ; p>0.05$ in the first and second group, respectively], in spike threshold $[-45.2 \pm 0.6 \mathrm{mV}(n=16) \mathrm{vs}-42.5 \pm 1.2 \mathrm{mV}(n=14) ; p>0.05$ in the first and second group, respectively], or in the firing probability at which cells of the two groups were examined $\left[P_{\mathrm{f}}\right.$ of $0.56 \pm 3.4(n=16)$ vs $0.51 \pm 3.4(n=14) ; p>0.05$ in the first and second group, respectively].

We subsequently analyzed the kinetics of subthreshold EPSPs recorded in the same neurons by measuring the half width of the EPSP, as an indication of its duration. Interneurons of the first group, with long EPSP-spike latencies and a low degree of spiketiming precision, were associated with long-lasting EPSPs (Fig. $1 C, D$, filled triangles) $(n=16)$. On the contrary, cells showing short EPSP-spike latencies and a high degree of spike-timing precision were associated with short-lasting EPSPs (Fig. 1C,D, filled circles) ( $n=13$; one cell was discarded because the stimulation artifact prevented an accurate measurement of the half width). EPSP kinetics has been shown to be an important determinant of EPSP-spike coupling in different neuronal populations (Fricker and Miles, 2000). Our data (for the pooled sample of long-latency and short-latency interneurons) show a significant correlation between EPSP half width and EPSP-spike latency (Fig. $1 C)(r=0.88 ; n=29 ; p<0.05)$ and between EPSP half width and the CV of the EPSP-spike latency distributions (Fig. 1D) $(r=0.56 ; n=29 ; p<0.05)$. This result is similar and consistent with the correlation between EPSP amplification and EPSP-spike latency (for the pooled pyramidal and interneuron 
populations) shown by Fricker and Miles (2000, compare with their Fig. 2D).

Overall, these data indicate that the kinetics of the EPSP is correlated with EPSP-spike coupling in interneurons, but do not indicate whether the variability of the half width of the EPSP is attributable to a large spread of a single kinetic population or whether multiple functional populations may be involved. Therefore, we subsequently examined this issue directly by studying the frequency distribution of the half width of subthreshold EPSPs evoked from a membrane potential of $-63.4 \pm 0.4$ in a large sample of stratum radiatum interneurons $(n=70)$. As is apparent from Figure $1 E$, the distribution was clearly polymodal, with at least two clear peaks, suggesting the presence of two functionally distinct cell populations. The impression from visual inspection of two components was confirmed by comparing nonlinear fits using a single Gaussian versus the sum of two or three Gaussians ( $F$ test; $p<0.001$; see Materials and Methods). We therefore concluded that two kinetically distinct populations of interneurons were present in the sample used in this study, which we termed fast and slow. However, it is clear that a partial overlap is present and that we need a threshold value for classification purposes. We decided to use the cutoff value of $100 \mathrm{msec}$, which is associated with reasonable errors that can be quantified by analyzing the ratio of the areas of the distribution belonging to the overlapping populations and delimited by the threshold value (Fig. $1 G$, inset; see also Materials and Methods). We subsequently ruled out the possibility that the two kinetic populations depended on the amplitude of the synaptic response. Indeed, no significant correlation was found between half width and EPSP amplitude $(r=-0.32 ; p>0.05 ; n=62)$ (Fig. $1 F)$, thus arguing against differential dendritic filtering of the EPSP, perhaps because of different locations of the activated synapses on the dendritic tree. In addition, the lack of correlation excludes the possibility that slower EPSPs are simply an artifactual consequence of larger-amplitude events driving the membrane potential to more depolarized potentials, which cause a stronger NMDAR-mediated component. On the contrary, this might be explained by an actual different proportion of AMPA versus NMDAR-mediated currents in the synaptic response, consistent with the properties of evoked EPSCs recorded in CA1 interneurons (Sah et al., 1990). Therefore, we subsequently investigated the role of NMDARs in setting the characteristics of slow versus fast interneurons.

\section{Functional diversity between slow and fast interneurons depends on synaptic activation of NMDARs}

We selectively blocked the NMDAR-mediated component of synaptic responses in 26 interneurons held at a membrane potential of $63.0 \pm 0.6 \mathrm{mV}(n=26)$, and compared their half width in control conditions and in the presence of D-AP-5 $(100 \mu \mathrm{M})$ (Fig. $2 A)$. D-AP-5 reduced the EPSP half width from $234 \pm 26.9$ to $81 \pm 11.2 \mathrm{msec}$ in slow interneurons $(n=15 ; p<0.05)$ and from $37.6 \pm 5.6$ to $24.6 \pm 3.0 \mathrm{msec}$ in fast interneurons $(n=11 ; p<$ $0.05)$. The effect of D-AP-5 was more pronounced on EPSPs with larger half widths in control conditions $(r=-0.64 ; p<0.05 ; n=$ 26) (Fig. $2 B$ ), indicating a larger impact of NMDAR activation in shaping the EPSPs of slow rather than fast interneurons. In 11 of 15 cases, D-AP-5 could convert slow interneurons (half width, $>100 \mathrm{msec}$ ) into apparent fast interneurons (half width, $<100$ msec). Furthermore, the kinetics of the D-AP-5-sensitive component was different in slow versus fast interneurons [268 \pm 21.9 msec for slow interneurons $(n=15)$ vs $143 \pm 15.1$ msec in fast interneurons $(n=10) ; p<0.05$ (in one cell this component was too small to allow a reliable measurement of the half width and was not used), see for example the traces in Fig. $2 A, b, d]$. We also ruled out the possibility that the NMDAR-dependent kinetics in slow interneurons was attributable to NMDAR-dependent polysynaptic transmission (Crepel et al., 1997) by examining the effect of membrane hyperpolarization on the evoked EPSP (Fig. $2 C)$. Hyperpolarization to $-90 \mathrm{mV}$ could reduce the half width of the EPSP of slow interneurons below the threshold of $100 \mathrm{msec}$ (half width, $220 \pm 20.9 \mathrm{msec}$ at $-63 \mathrm{mV}$ vs $54.7 \pm 8.7 \mathrm{msec}$ at -90 $\mathrm{mV} ; n=6 ; p<0.05$ ) (Fig. $2 C$ ), indicating that the kinetics of the EPSP in these cells depends on postsynaptic NMDARs located in the membrane of the recorded neuron and not in other cells of the network.

If the properties of EPSP-spike coupling depend on the kinetics of the EPSP, which, in turn, depends on NMDAR activation, a testable prediction is that the properties of EPSP-spike coupling in slow interneurons should be strongly affected by NMDAR blockade. As shown in Figure 2D, this prediction was confirmed experimentally. After adjustment of stimulation intensity to maintain the same probability of firing as in control conditions $\left(P_{\mathrm{f}}\right.$ of $\sim 0.5$ ), application of D-AP-5 reduced EPSP-spike latencies and reduced the variability of spike timing (Fig. $2 D)(n=4)$. Mean EPSP-spike latencies and CVs calculated from the distributions of each individual cell decreased from $50.9 \pm 12.4 \mathrm{msec}$ and $0.79 \pm 0.04$ to $9.6 \pm 2.6 \mathrm{msec}$ and $0.31 \pm 0.05$, respectively $(n=$ 4) $(p<0.05)$. These data indicate that NMDAR activation is critical for determining spike-timing properties of slow interneurons. An alternative possibility is raised by the work of Otmakhova and Lisman (1999) who reported that, in CA1 pyramidal neurons, temporoammonic input has a larger NMDAR component than the Schaffer collateral input. Therefore, we evoked EPSPs triggered by the stimulation of different hippocampal layers to determine whether different pathways could convert slow into fast interneurons or vice versa. As apparent from Figure $2 E$, the position of the stimulating electrode was not a relevant factor in discriminating slow versus fast interneurons, suggesting that, under our experimental conditions, the main factor involved is likely to be the postsynaptic cell type and not the stimulated pathway.

\section{Effect of NMDAR blockade on action potential generation}

Application of D-AP-5 $(100 \mu \mathrm{M})$ revealed another difference between slow and fast interneurons, as shown in Figure $3 A$. NMDAR blockade severely reduced the ability of slow interneurons to generate action potentials, without affecting the initial slope of the EPSP. In the example shown in Figure $3 A$, at a firing probability $\sim 0.5$, action potential generation was entirely dependent on NMDAR activation. On the contrary, no effect of D-AP-5 on firing could be seen in fast interneurons (Fig. 3, compare $A$ and $C)$. At higher stimulation intensities, slow interneurons characteristically produced multiple spikes and late action potentials were selectively abolished by D-AP-5. In contrast, fast cells consistently limited their firing to single action potentials, which were unaffected by the drug application (Fig. $3 B, D$ ). From a total of 14 cells, no significant effect was seen on the initial slope of the EPSP in either type of cell (EPSP slope in the presence of D-AP-5 was $97.7 \pm 8.3$ and $96.0 \pm 7.0 \%$ of control in seven slow and seven fast interneurons, respectively). However, NMDAR blockade could consistently reduce firing in slow interneurons but not in fast cells 
A

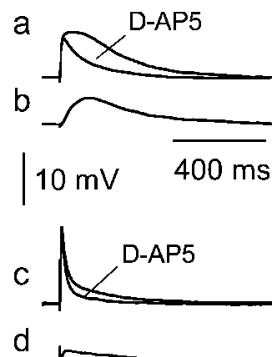

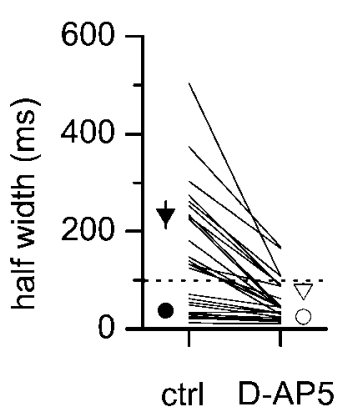

B

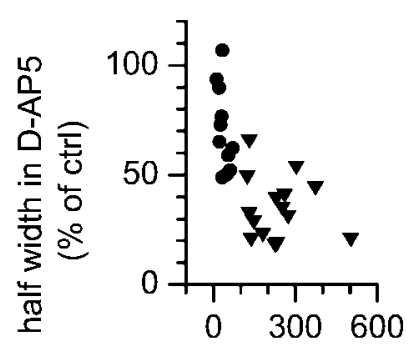

half width in ctrl (ms)
C

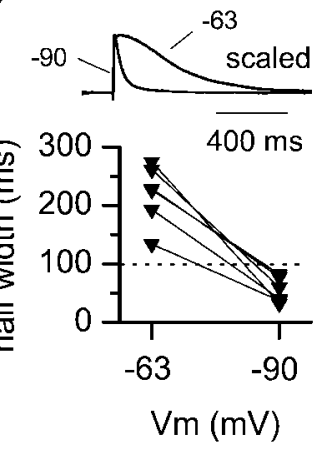

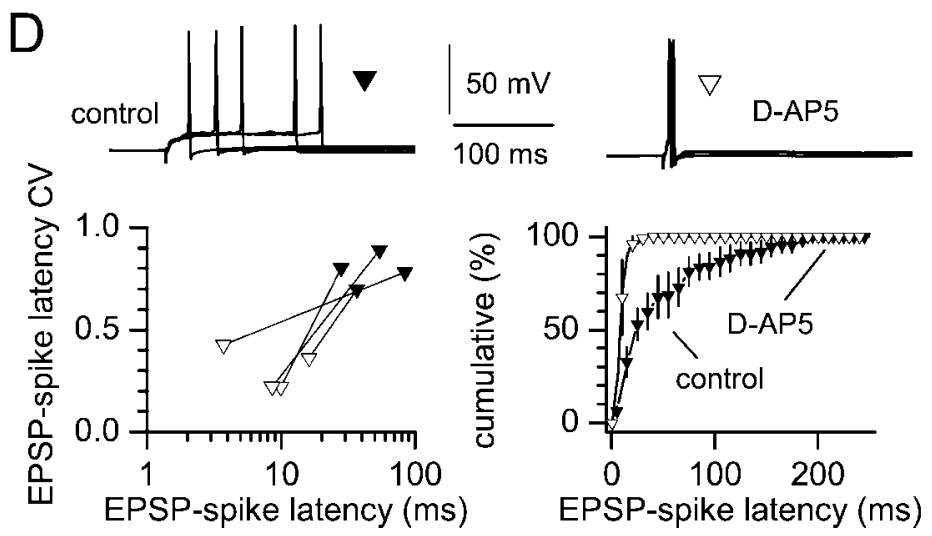
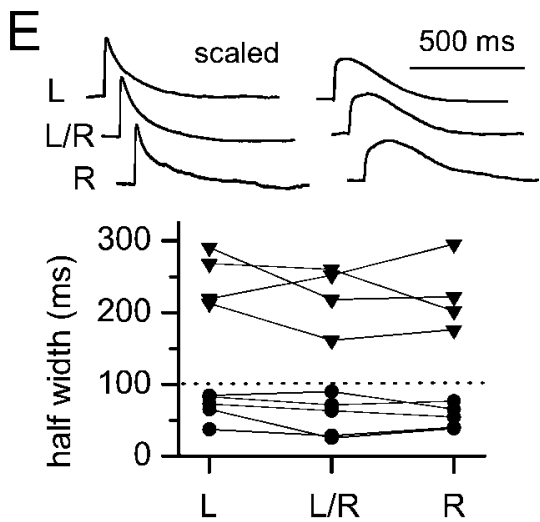

Figure 2. NMDAR contribution to EPSPs in slow and fast interneurons. $A$, Effect of D-AP-5 $(100 \mu \mathrm{M})$ on EPSP half width in slow and fast interneurons. Insets show averaged traces in control and after D-AP-5 application $(a, c)$ and the D-AP-5-sensitive component for slow $(b)$ and fast $(d)$ interneurons. The summary graph on the right shows the individual results (lines) and the overall change in half width in slow (triangles) and fast (circles) interneurons. $B$, D-AP-5 effect depends on the original half width. Notice that slow EPSPs are more affected by D-AP-5 compared with fast EPSPs. $C$, Voltage dependency of slow EPSPs at resting $(-63 \mathrm{mV})$ and hyperpolarized $(-90 \mathrm{mV})$ potentials excludes polysynaptic transmission. Inset shows averaged traces in the two conditions, after scaling to the peak. $D$, D-AP-5 application converts EPSP-spike coupling properties of slow interneurons. Notice the decrease in both EPSP-spike latency and in the CV of the latency distribution (left plot). On the right, the complete EPSP-spike latency distributions at a $P_{\mathrm{f}}$ of $\sim 0.5$ are shown in controls ( filled triangles) and after D-AP-5 application (open triangles). Insets show five sweeps in control conditions (left) and after the addition of the drug (right). E, Classification of slow ( filled triangles) and fast (filled circles) interneurons is not a consequence of the stimulated pathway. A summary plot of EPSP half width is shown after stimulation of stratum lacunosum-moleculare $(L)$, the border between stratum lacunosum-moleculare and stratum radiatum $(L / R)$, and stratum radiatum $(R)$. Averaged traces are shown for the different conditions. Dotted lines indicate the $100 \mathrm{msec}$ threshold.

[number of spikes was reduced to $35.4 \pm 11.6 \%$ of control in seven slow interneurons $(p<0.05)$ compared with $124.2 \pm 24.0 \%$ in seven fast interneurons $(p>0.05)]$. These results show that slow interneurons crucially depend on NMDAR activation for spike generation. Indeed, in these cells, D-AP-5 is effective in reducing or completely preventing synaptically evoked firing. On the contrary, no reduction of firing by D-AP-5 was observed in fast interneurons, regardless of the stimulation strength of the synaptic input.

\section{Integration and coincidence detection in slow and fast interneurons}

The different EPSP kinetics in slow and fast interneurons predicts that the two groups of cells would process synchronous and asynchronous synaptic input differently. Kinetically fast EPSPs are usually efficient coincidence detectors but less effective synaptic integrators, whereas the opposite holds for slow EPSPs (Konig et al., 1996; Geiger et al., 1997). Therefore, we examined the computational differences between slow and fast interneurons by calculating the probability of firing after stimulation of two independent pathways at different interstimulus delays. The stimulation strength of the isolated inputs was set at minimal firing probability (between 0 and 0.2 ) to determine the time frame over which synchronous activation yielded a higher firing probability. As shown by the plots in Figure $4, A$ and $B$, firing probability decayed gradually in slow interneurons $(n=4)$ but rapidly in fast cells $(n=5)$ as the interpulse interval was lengthened. As discussed before (Fig. 3 ), application of D-AP-5 reduced the probability of firing in slow interneurons, so the effect of NMDAR blockade was examined after readjusting the stimulation intensity to match the control level during coincident stimulation. D-AP-5 did not affect significantly the responses of fast cells $(n=5$ cells in control vs $n=4$ cells in D-AP-5; $p>0.05$ for the entire $0-450$ msec interval) (Fig. 4B), whereas it decreased integration in slow cells ( $n=4$ cells in control vs $n=3$ cells in D-AP-5; $p<$ 0.05 for the 50-300 msec interval) (Fig. 4A). This result indicates that NMDAR-dependent integration is prominent in slow cells but is nearly absent at comparable time windows in fast interneurons. In both cell types, however, the nonNMDAR-mediated part of the EPSP alone is sufficient to allow efficient coincidence detection of synchronous synaptic input. 

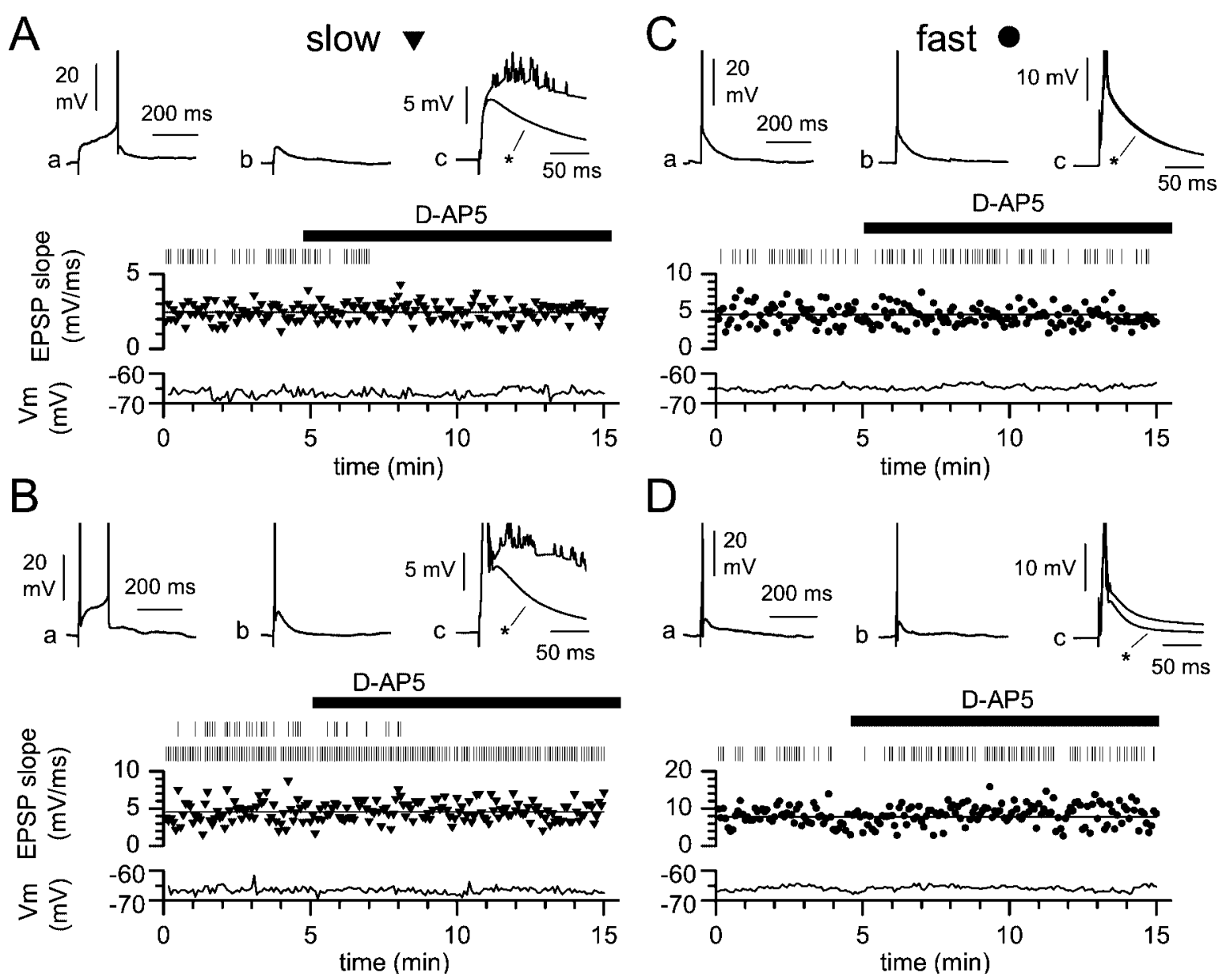

Figure 3. Firing is NMDAR-dependent in slow interneurons but not in fast cells. Simultaneous plots of membrane potential (bottom), initial EPSP slope (middle), and spike raster (top) in four different cells. $A$, Slow interneurons at low-intensity stimulation as indicated by the EPSP slope value: notice that firing is completely abolished by D-AP-5. B, At higher stimulation intensities, multiple spikes are generated; both early and late spikes are produced, but only late spikes show D-AP-5 sensitivity. $C, D$, Fast interneurons produce only single spikes, which are insensitive to D-AP-5 despite the large EPSP slope values. D-AP-5 (100 $\mu \mathrm{M})$ application is indicated by the black bar. Insets show single sweeps in the control condition $(a)$, in the presence of D-AP-5 (b), and average traces superimposed $(c)$. The asterisk indicates the traces in the presence of the drug.

\section{Postsynaptic targets of slow and fast interneurons and unitary GABAergic IPSCs}

The functional differences in the processes leading to the activation of fast and slow interneurons are likely to impact and shape feedforward GABAergic input to the CA1 region. We performed paired recordings from interneurons and pyramidal cells with two aims: first, to establish whether both types of interneurons target pyramidal cells, and second, to compare the basic properties of unitary IPSCs (uIPSCs) originating from the different cell types. This set of experiments was performed in two steps: first, a uIPSC was recorded from the pyramidal cell of the pair in a bicuculline-free external solution, then bicuculline $(20 \mu \mathrm{M})$ was applied and EPSPs were collected from the interneuron of the pair after stimulation of excitatory afferents. The pyramidal cell was held in voltage clamp at $-70 \mathrm{mV}$, and the interneuron was recorded under current-clamp configuration. Unitary connections were defined as short-latency synaptic currents that followed an action potential triggered by current injection in the presynaptic interneuron (mean latency was $1.9 \pm 0.2 \mathrm{msec} ; n=22$ ). Figure $5 A, B$ illustrates two representative recordings obtained from a slow and a fast interneuron, respectively. No significant difference could be found in the amplitude, 10-90\% rise time, time constant of decay (Fig. 5C1-C3), or paired-pulse ratio (100 msec interpulse interval) (Fig. 5D1,D2) of uIPSCs originating from slow versus fast interneurons. Amplitudes of uIPSCs were $30.9 \pm 10.0 \mathrm{pA}$ $(n=11)$ for slow interneurons and $19.5 \pm 7.7 \mathrm{pA}(n=11)$ for fast interneurons $(p>0.05), 10-90 \%$ rise times were $5.1 \pm 0.8$ $\operatorname{msec}(n=11)$ for slow interneurons and $5.6 \pm 0.9(n=11)$ for fast interneurons $(p>0.05)$, decay $\tau$ were $23.2 \pm 3.4 \mathrm{msec}(n=$ 11) for slow interneurons and $23.4 \pm 2.5 \mathrm{msec}(n=11)$ for fast interneurons $(p>0.05)$, and paired-pulse ratios were $0.96 \pm$ 0.04 for slow interneurons and $1.24 \pm 0.25$ for fast interneurons $(p>0.05)$. No statistically significant correlation was present between the aforementioned parameters of the uIPSCs and the half width of the EPSPs of all of the pooled interneurons (amplitude: $r=0.16, p>0.05$; rise time: $r=-0.08, p>0.05$; decay: $r=0.05, p>0.05$; paired-pulse ratio: $r=-0.19, p>$ $0.05 ; n=22$ ) (Fig. $5 C, D)$.

In 11 cases (from five slow and six fast interneurons) the uIPSC was monitored during bicuculline application and was virtually abolished (Fig. 5D1), indicating that the recorded connection was mediated by $\mathrm{GABA}_{\mathrm{A}}$ type receptors.

These results show that both fast and slow interneurons target CA1 pyramidal cells and, therefore, participate in feedforward inhibition and in the regulation of the excitatory output of the CA1 hippocampus. Furthermore, the similarity of 

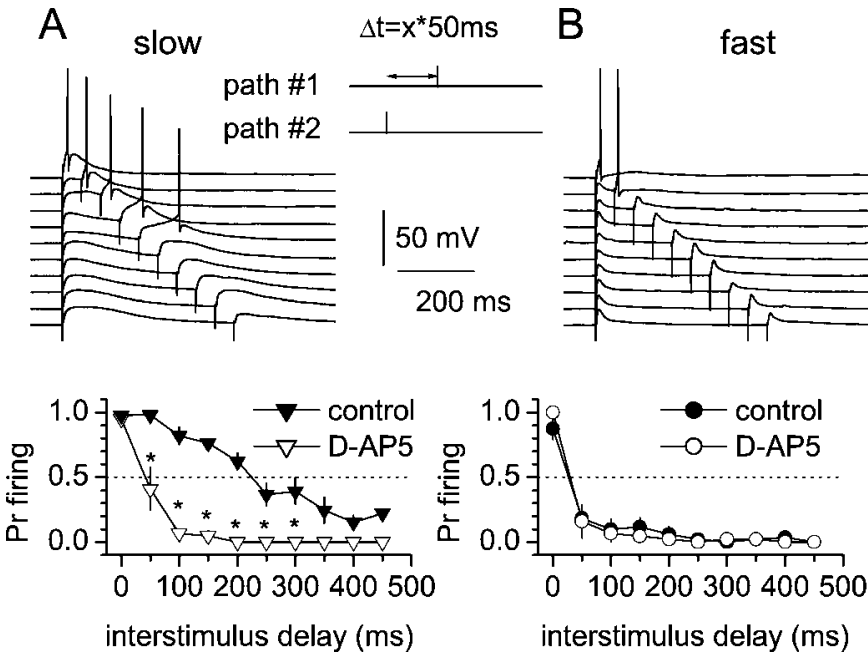

Figure 4. Integration of synaptic input is different in slow versus fast interneurons. $A$, Summary plot showing the integrative properties of slow interneurons. Integration is NMDAR-dependent ( filled triangles, control; open triangles, D-AP-5). The top panel displays single sweeps for each interstimulus delay. $B$, Properties of fast interneurons in control (filled circles) and D-AP-5 (open circles). Notice the abrupt decrease in firing probability with the desynchronization of the input and the lack of effect of the drug. The top panel shows single traces for each interval tested. Notice also the prolongation and amplification of the second EPSP in traces 4 and 5 of $A$, suggesting the involvement of intrinsic conductances. Dotted lines indicate the $P_{\mathrm{f}}=0.5$ level, for reference.

the basic properties of the uIPSCs suggests overlap in the location of the postsynaptic membrane target domains (Maccaferri et al., 2000). As shown by the examples in Figure $6 A, B$, despite the heterogeneity in the shape and orientation of the somatodendritic structure, both slow and fast interneurons appeared to innervate selectively the dendritic compartment of pyramidal cells.

\section{Spike timing of slow and fast interneurons during principal cell activation}

The specific role played by either interneuron type in regulating postsynaptic functions will depend on the relative time of firing with respect to synaptic responses occurring in pyramidal neurons. For example, the long EPSP-spike latency typical of slow interneurons could result in an unconventional feedforward mechanism. Indeed, the delayed activation of slow interneurons could produce delayed GABAergic input, which could temporally overlap with feedback inhibition and even follow firing in the postsynaptic targets. However, contrary to feedback inhibition, this type of "delayed feedforward" inhibition would not be driven by firing activity in the target cells. In contrast, the spike-timing properties of fast interneurons suggest early activation with respect to principal cells EPSPs, as in "classical" feedforward mechanisms (Buzsaki, 1984). We verified that action potentials in slow and fast interneurons had different delays relative to pyramidal cell spikes by performing double recordings from interneurons and principal cells during activation of the Schaffer collaterals. Stimulation intensity was adjusted to reach a probability of firing of $\sim 0.5$ in the interneurons $(0.63 \pm 0.08$ in slow interneurons and $0.61 \pm 0.05$ in fast interneurons; $n=4$ in each cell group). Both pyramidal cell and interneurons were held at approximately -63 $\mathrm{mV}$. In trials that evoked spikes in both interneurons and pyramidal cells, firing in slow interneurons could either precede (negative interspike delay) or follow (positive interspike delay) action potentials in pyramidal cells, as shown by the distribution of the interspike delays (Fig. $7 A$ ). In contrast, firing in fast interneurons always preceded action potentials in principal cells, as indicated by the negative interspike delay in the distribution. In addition, we also analyzed firing in interneurons with respect to EPSP timing in pyramidal cells. Interneuron spike timing was expressed as the percentage of peak EPSP amplitude of the principal neuron, measured at the time of the action potential peak in the interneuron (Fig. $7 B$ ). These results show that action potentials in slow and fast interneurons occurred at different EPSP phases. Whereas slow interneurons were primarily active during the decay of the EPSPs, fast cells clustered their action potentials in the rising phase, suggesting a different network role for the two groups of GABAergic cells. Finally, it is interesting to note that the half width of the EPSP recorded in pyramidal cells was shorter than the value measured in slow interneurons $(86.7 \pm$ 18.9 vs $219 \pm 14.5 \mathrm{msec}$, respectively; $n=4$ double recordings; $p<0.05)$ but longer than the half width of the EPSP of fast cells ( $89 \pm 19.3$ vs $36.5 \pm 9.1 \mathrm{msec} ; n=4$ double recordings; $p<0.05$ ). Our impression is that the NMDAR component of the EPSP is more prominent in slow interneurons than in pyramidal cells.

\section{DISCUSSION}

The main findings of this study are that: (1) feedforward hippocampal interneurons comprise two putative functionally distinct cell types (slow and fast interneurons) with different spike timing and integrative properties, (2) the functional differences between these two putative populations depend on the activation of NMDARs, (3) both slow and fast interneurons analyzed in this study converge onto pyramidal cell dendrites and produce similar $\mathrm{GABA}_{\mathrm{A}}$ receptor-mediated $\mathrm{uIPSC}$, and (4) activation of slow and fast interneurons occurs at specific phases of pyramidal cell EPSPs.

Precision of spike timing in interneurons is believed to play an important role in network oscillations at behaviorally relevant frequencies (Fricker and Miles, 2001). Our results suggest the existence of a functionally novel type of interneuron that we have referred to as a slow interneuron, which displays spike-timing properties very different from those of neocortical fast-spiking cells (Galarreta and Hestrin, 1999; Gibson et al., 1999, 2001; but see also Jones and Buhl, 1993) or other previously described fast hippocampal interneurons (Geiger et al., 1997; Fricker and Miles, 2000). Our interpretation is based on the analysis of the frequency distribution of the half width of the EPSP in 70 interneurons, which is well fitted by a sum of two, but not three or one, Gaussians (see Materials and Methods). The functional properties of fast interneurons match very well the results reported by Fricker and Miles (2000) for the cell types they referred to as "typical" interneurons. It is interesting to note that Fricker and Miles (2000) preselected their target cells based on the stellate orientation of the dendrites, whereas we did not. This might explain our finding of a second population of slow interneurons. Also, we explored a younger and more restricted postnatal stage, which might be associated with different NMDAR expression, composition, properties, and density (McBain and Mayer, 1994; Dingledine et al., 1999). Finally, we examined EPSP-spike coupling from membrane potentials closer to rest (approximately $-63 \mathrm{mV}$ ), whereas Fricker and Miles (2000) studied small EPSPs originating from subthreshold potentials $(\sim-45 \mathrm{mV})$ at which different membrane conductances may be active. In their study, a few atypical interneurons with long latencies were reported, which might correspond to our slow interneurons. However, it 

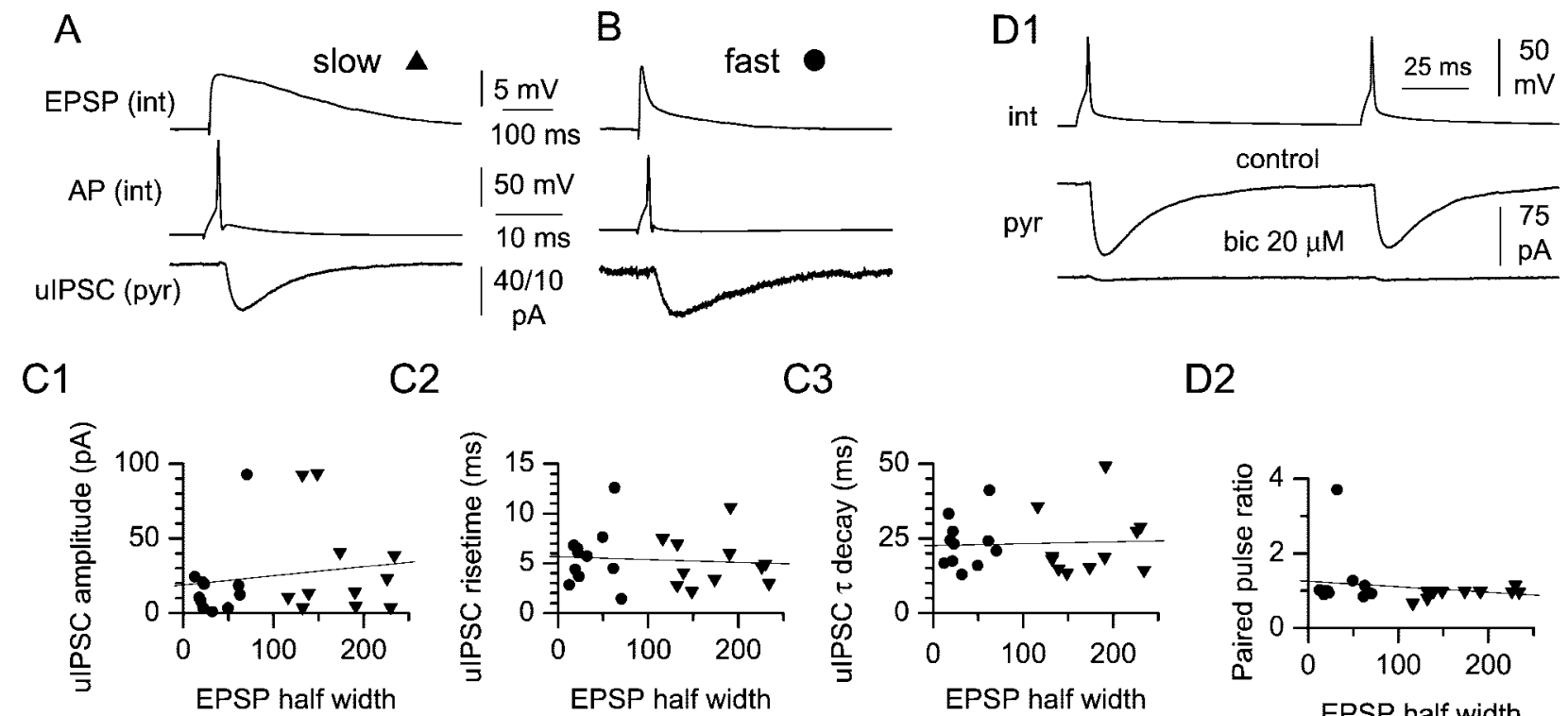

C3

D2

Figure 5. uIPSCs originating from slow and fast interneurons have similar basic properties. A, Averaged uIPSCs recorded from a pyramidal cell (bottom trace) in response to a spike in the presynaptic interneuron (middle trace). Note the slow kinetics of the evoked EPSP recorded from the interneuron after the addition of bicuculline ( $20 \mu \mathrm{M}$ ) (top trace). $B$, Same protocol as in $A$ applied to a fast interneuron. $C$, Summary plots relating EPSP kinetics to basic uIPSC properties. (triangles, slow interneurons; circles, fast interneurons). No significant correlations could be found in the case of uIPSC amplitude (C1), rise time (C2), and decay time constant (C3). D, Paired-pulse protocol in control and after the addition of bicuculline (bic) (D1). pyr, Pyramidal cell; int, interneuron. Note the virtual abolishment of the response. D2, Summary graph relating paired-pulse ratio to EPSP kinetics.

is also possible that spike timing in slow interneurons is voltage-dependent.

What are the molecular mechanisms underlying the difference between slow and fast interneurons? A possible explanation is that slow and fast interneurons differ in the proportion of NMDA versus AMPA receptor components of their synaptic currents, which can account for diversity of EPSP kinetics and, hence, spike timing and synaptic integration. However, additional possibilities cannot be excluded. For example, different NMDAR subunits with specific kinetics (Dingledine et al., 1999; Cull-Candy et al., 2001; Lei and McBain, 2002) could be expressed and shape the time course of the EPSP. This hypothesis would fit very well with the difference in kinetics of the D-AP-5-sensitive component of the EPSP in fast and slow cells. Alternatively, NMDAR activation could act indirectly by providing the depolarization needed to activate or depress a set of cell type-specific intrinsic conductances, ultimately leading to cell type-specific shaping of the EPSPs (Fricker and Miles, 2000). At the moment, we do not have elements to favor one explanation over the other. Both mechanisms are potentially equally valid and might even interact.

Our results also demonstrate a strong NMDAR-dependent integration of synaptic input in slow interneurons compared with fast cells. This mechanism could be involved in several situations that require time-prolonged firing during asynchronous activity. For example, "delayed-period activity" (Fuster and Alexander, 1971), which is believed to be the neuronal correlate of working memory, has been suggested to depend crucially on the synaptic ratio of NMDA/non-NMDAR components in prefrontal cortex circuits (Wang, 1999; Compte et al., 2000) and to require a strong NMDAR-mediated synaptic component (Lisman et al., 1998). In the hippocampus, novel sensory stimuli can evoke neuronal responses persisting after the stimulus is removed (Vinogradova, 1984; Watanabe and Niki, 1985; Colombo and Gross, 1994; Fried et al., 1997). Therefore, slow interneurons could act as the main source of GABAergic input to the dendrites of pyramidal neurons during prolonged asynchronous activity related to the detection of novelty (Lisman and Otmakhova, 2001) or other important cognitive tasks.

Are slow and fast interneurons anatomically distinct or the same type of cell in different functional states (Parra et al., 1998)? The two cell types could not be assigned simply to different anatomical classes. For example, it is possible that perforantpath- and Schaffer-associated interneurons (Vida et al., 1998) coexist within slow cells, whereas fast interneurons may represent Schaffer-associated interneurons and neurogliaform cells (Vida et al., 1998). In any case, the situation is likely to be complex, because bidirectional modulation of NMDAR activity could account for functional heterogeneity among morphologically similar interneurons. Activation of metabotropic glutamate receptor 5 receptors, which are expressed in interneurons (Romano et al., 1995; Lujan et al., 1996; Van Hooft et al., 2000) enhances NMDAR function (Mannaioni et al., 2001), and could therefore convert fast into slow interneurons, whereas production of nitric oxide or activity-dependent acidification of the extracellular fluid (Dingledine et al., 1999) could reduce the NMDAR contribution to the EPSP.

The properties of the recorded UIPSCs and the anatomical reconstructions indicate that the majority of the slow and fast interneurons tested in this study are likely to target predominantly dendrites. Perisomatic targeting cells such as basket cells are known to exist outside stratum pyramidale (Freund and Buzsaki, 1996). However, to our knowledge, the relative proportion of these cells with respect to dendritic-targeting interneurons of stratum radiatum has not been quantified and remains, at present, unknown. Perisomatic targeting cells produce postsynaptic IPSCs with fast kinetics, because of their proximal targeting (Maccaferri et al., 2000; Jensen and Mody, 2001). Very few $(<20 \%)$ of the uIPSCs recorded in our sample of 22 cells had comparable kinetics, suggesting more distal contact sites for the remaining majority. In addition, we found no direct evidence for 

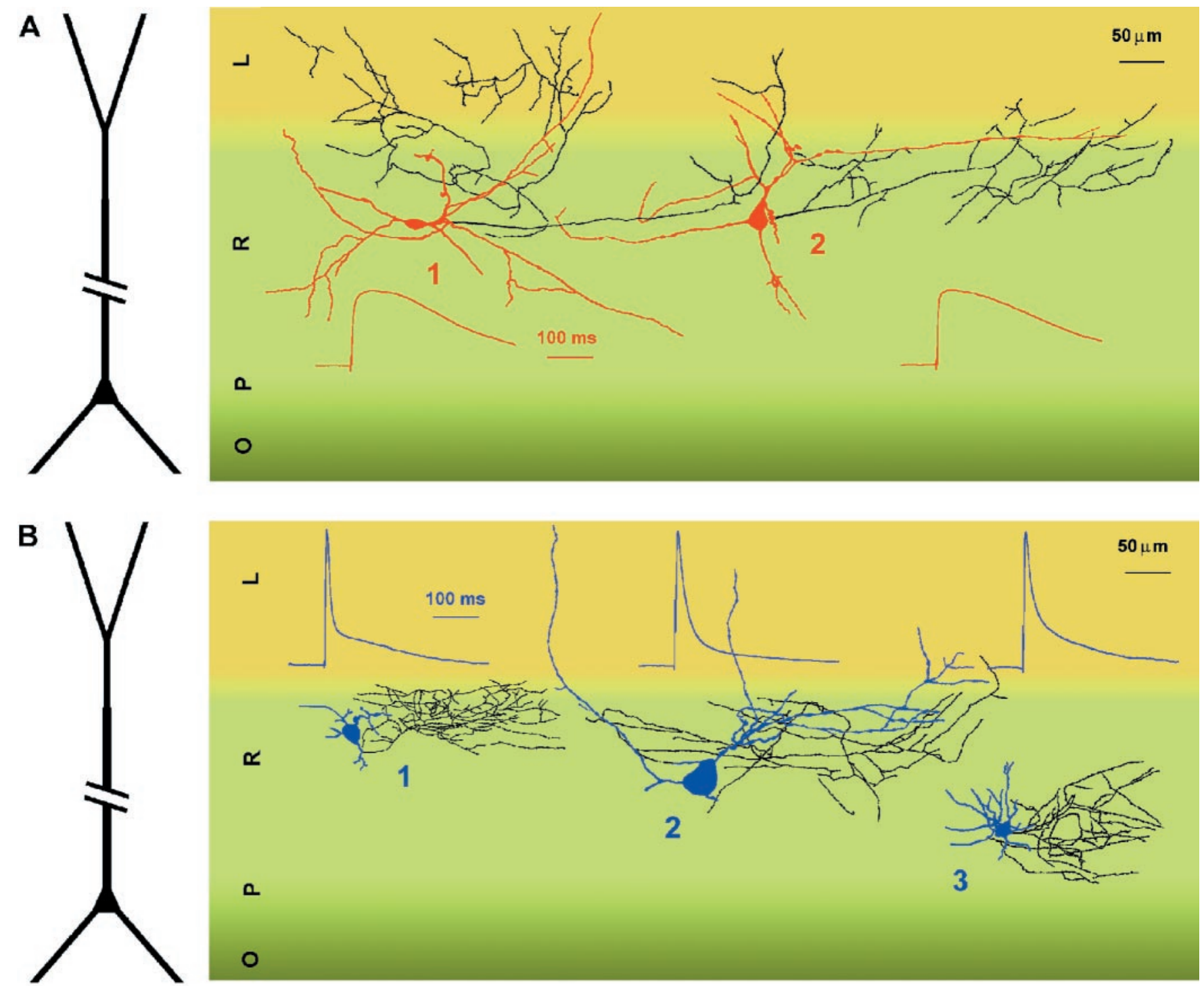

Figure 6. Anatomical reconstruction of slow (red) and fast (blue) interneurons and averaged scaled EPSPs recorded in the same cells. Axons are shown in black. $A$, Slow interneurons could target stratum lacunosum-moleculare $(L$, cell 1$)$ or stratum radiatum $(R$, cell 2$)$. $B$, Fast interneurons more commonly limited their innervation to stratum radiatum (cells 1-3). Different hippocampal layers are shown in different shades of green/yellow. $O$, Stratum oriens; $P$, stratum pyramidale. A representation of the structure of a pyramidal cell is shown at the left for reference.

basket or axoaxonic cells in our reconstructions. However, this does not exclude the existence of perisomatic-targeting slow or fast cells. What roles in dendritic feedforward inhibition could be specifically performed by fast and slow interneurons? One clue is that spikes generated by the different cell types were temporally segregated to specific phases of the EPSP observed in principal cells, thus suggesting different network functions. However, given the small conductance of uIPSCs recorded at the soma, dendritic feedforward inhibition from fast interneurons is unlikely to be effective in the regulation of firing initiated at the axon, as shown by recent work by Pouille and Scanziani (2001). It would, however, be expected to exert a dramatic control over dendritic initiation of action potentials (Spruston et al., 1995; Kamondi et al., 1998) during network rhythms associated with strong glutamatergic input such as sharp waves (Buzsaki, 1986; Ylinen et al., 1995) or interictal discharges (Matsumoto and Ajmone-Marsan, 1964). GABA release after action potentials in fast interneurons could play an important role in regulating dendritic spike gener- ation, which most commonly occurs during the early phase of the somatic pyramidal neuron EPSP (Golding and Spruston, 1998). In contrast, GABA release from slow interneurons could provide a mechanism to regulate pyramidal cell membrane potential during later phases, coincident with maximal activity of postsynaptic NMDARs and, therefore, modulate $\mathrm{Ca}^{2+}$ dynamics (Spruston et al., 1995) and the induction of synaptic plasticity (Bliss and Collingridge, 1993).

It is also interesting to note that delayed firing activity in slow interneurons can be reduced or eliminated by disruption of NMDAR-mediated input. Under these conditions, indeed, even raising the excitatory input to compensate for the loss only triggers early action potentials (Fig. 3). This observation suggests a higher vulnerability of delayed inhibition originating from slow interneurons compared with GABAergic input originating from fast cells. This situation may occur under pathological conditions of NMDAR hypoactivity, such as, potentially, schizophrenia (Olney et al., 1999). Our data would predict a predominant loss of 

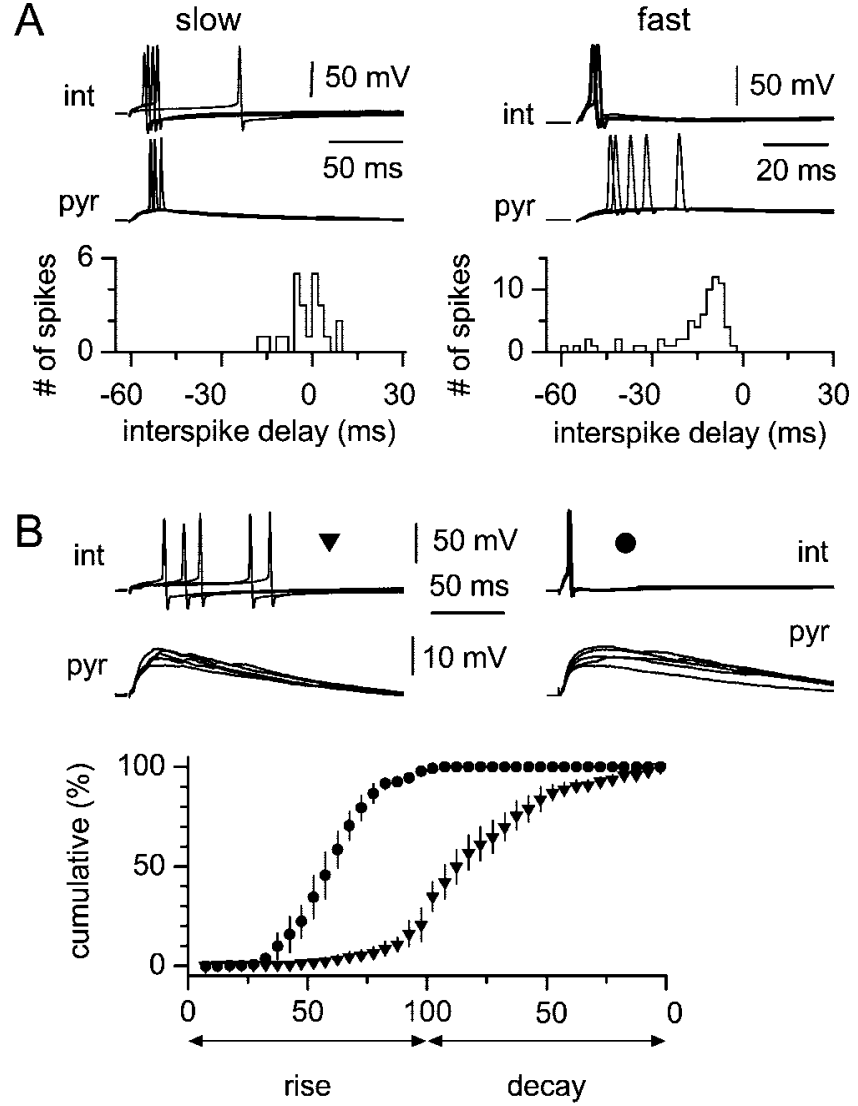

interneuron spike timing (\% pyrEPSP peak)

Figure 7. Relative spike timing of interneurons and pyramidal cells during CA3 $\rightarrow$ CA1 transmission. $A$, Left, Interspike interval distribution between a slow interneuron and a pyramidal cell; notice that some spikes in the interneuron precede (negative values of the distribution), while others follow (positive values) firing in the pyramidal cell. The inset shows five sweeps recorded simultaneously from both cells. Right, Similar experiment performed on a fast cell. Notice that firing in the interneuron always precedes firing in the pyramidal cell, and that only negative values are present in the distribution. B, Spike timing in slow (left) and fast (right) interneurons relative to EPSP rise and decay in simultaneously recorded pyramidal cells; five simultaneous sweeps are shown for each double recording. The summary graph shows cumulative distributions of slow (triangles) and fast (circles) interneurons that are superimposed. The $x$-axis indicates the spike timing of the interneuron expressed as the normalized pyramidal cell EPSP amplitude, measured at the time of the interneuron spike. Note that slow interneurons are mostly active during the decay phase, whereas fast cells fire exclusively during the rising phase. pyr, Pyramidal cell; int, interneuron.

late, asynchronous GABAergic input, while early, synchronous inhibition provided by fast interneurons would be substantially spared. Indeed, functional studies from schizophrenic patients have shown hippocampal hyperactivity at rest (Heckers, 2001), consistent with the possibility of a functional disruption of inhibitory circuits (Olney et al., 1999).

Finally, the overall scenario could be even more complex by considering the effect of feedforward inhibition on the interneurons themselves (Pouille and Scanziani, 2001). Generation of late spikes in slow interneurons could be under network control, and the functional distinction between slow and fast interneurons might apply primarily to conditions in which the efficacy of postsynaptic inhibition is partly reduced.
In conclusion, in this work we show a novel aspect of functional diversity in hippocampal interneurons that is likely to have profound implications for the regulation of feedforward GABAergic circuits and network rhythms during normal brain function and/or during disease. Furthermore, the essential role of synaptic activation of NMDAR opens the possibility of a complex regulation of temporally specific GABAergic input by expression of specific NMDAR subunits and by endogenous or exogenous pharmacological modulation.

\section{REFERENCES}

Alger BE, Nicoll RA (1982) Feed-forward dendritic inhibition in rat hippocampal pyramidal cells studied in vitro. J Physiol (Lond) 328:105-123.

Bliss TV, Collingridge GL (1993) A synaptic model of memory: longterm potentiation in the hippocampus. Nature 361:31-39.

Borst JGG, Helmchen F, Sakmann B (1995) Pre- and post-synaptic whole-cell recordings in the medial nucleus of the trapezoid body of the rat. J Physiol (Lond) 489:825-840.

Brew HH, Forsythe ID (1995) Two voltage-dependent $\mathrm{K}^{+}$conductances with complementary functions in postsynaptic integration at a central auditory synapse. J Neurosci 15:8011-8022.

Buzsaki G (1984) Feed-forward inhibition in the hippocampal formation. Prog Neurobiol 22:131-153.

Buzsaki G (1986) Hippocampal sharp waves: their origin and significance. Brain Res 398:242-252.

Colombo M, Gross CG (1994) Responses of inferior temporal cortex and hippocampal neurons during delayed matching to sample in monkeys (Macaca fascicularis). Behav Neurosci 108:443-455.

Compte A, Brunel N, Goldman-Rakic PS, Wang XJ (2000) Synaptic mechanisms and network dynamics underlying spatial working memory in a cortical network model. Cereb Cortex 10:910-923.

Crepel V, Khazipov R, Ben-Ari Y (1997) Blocking GABA inhibition reveals AMPA- and NMDA-receptor mediated polysynaptic responses in the CA1 region of the rat hippocampus. J Neurophysiol 77:2071-2082.

Csicsivari J, Hirase H, Czurko A, Buzsaki G (1998) Reliability and state dependence of pyramidal cell-interneuron synapses in the hippocampus: an ensemble approach in the behaving rat. Neuron 21:179-189.

Cull-Candy S, Brickley S, Farrant M (2001) NMDA receptor subunits: diversity, development, and disease. Curr Opin Neurobiol 11:327-335.

Davies CH, Starkey SJ, Pozza MF, Collingridge GL (1991) GABA autoreceptors regulate the induction of LTP. Nature 349:609-611.

Dingledine R, Borges K, Bowie D, Traynelis SF (1999) The glutamate receptor ion channels. Pharmacol Rev 51:7-61.

Freund TF, Buzsaki G (1996) Interneurons of the hippocampus. Hippocampus 6:347-470.

Fricker D, Miles R (2000) EPSP amplification and the precision of spike timing in hippocampal neurons. Neuron 28:559-569.

Fricker D, Miles R (2001) Interneurons, spike timing, and perception. Neuron 32:771-777.

Fried I, MacDonald KA, Wilson CL (1997) Single neuron activity in human hippocampus and amygdala during recognition of faces and objects. Neuron 18:753-765.

Fuster J, Alexander G (1971) Neuron activity related to short-term memory. Science 173:652-654.

Galarreta M, Hestrin S (1999) A network of fast-spiking cells in the neocortex connected by electrical synapses. Nature 402:72-75.

Galarreta M, Hestrin S (2001) Spike transmission and synchrony detection in networks of GABAergic interneurons. Science 292:2295-2299.

Geiger JRP, Lubke J, Roth A, Frotscher M, Jonas P (1997) Submillisecond AMPA receptor-mediated signaling at a principal neuron interneuron synapse. Neuron 18:1009-1023.

Gibson JR, Beierlein M, Connors BW (1999) Two networks of electrically coupled inhibitory neurons in neocortex. Nature 402:75-79.

Golding NL, Spruston N (1998) Dendritic sodium spikes are variable triggers of axonal action potentials in hippocampal CA1 pyramidal neurons. Neuron 21:1189-1200.

Heckers S (2001) Neuroimaging studies of the hippocampus in schizophrenia. Hippocampus 11:520-528.

Horn R (1987) Statistical methods for models discrimination: application to gating kinetics and permeation of acetylcholine receptor channel. Biophys J 51:255-263.

Jensen K, Mody I (2001) L-type $\mathrm{Ca}^{2+}$ channel-mediated short-term plasticity of GABAergic synapses. Nat Neurosci 4:975-976.

Jones RS, Buhl EH (1993) Basket-like interneurons in layer II of the entorhinal cortex exhibit a powerful NMDA-mediated synaptic excitation. Neurosci Lett 149:35-39.

Kamondi A, Acsady L, Buzsaki G (1998) Dendritic spikes are enhanced by cooperative network activity in the intact hippocampus. J Neurosci 18:3919-3928. 
Knowles WD, Schwarzkroin PA (1981) Local circuit synaptic interactions in hippocampal brain slices. J Neurosci 1:318-322.

Koch C, Segev I (2000) The role of single neurons in information processing. Nat Neurosci 3:1171-1177.

Konig P, Engel AK, Singer W (1996) Integrator or coincidence detector? The role of the cortical neuron revisited. Trends Neurosci 19:130-137.

Koyano K, Funabiki K, Ohmori H (1996) Voltage-gated ionic currents and their roles in timing coding in auditory neurons of the nucleus magnocellularis of the chick. Neurosci Res 26:29-45.

Lei S, McBain CJ (2002) Distinct NMDA receptors provide differential modes of transmission at mossy-fiber interneuron synapse. Neuron 33:921-933.

Lisman JE, Otmakhova NA (2001) Storage, recall, and novelty detection of sequences by the hippocampus: elaborating on the SOCRATIC model to account for normal and aberrant effects of dopamine. Hippocampus 11:551-568.

Lisman JE, Fellous J-M, Wang X-J (1998) A role for NMDA-receptor channels in working memory. Nat Neurosci 1:273-275.

Lujan R, Nusser Z, Roberts JD, Shigemoto R, Somogyi P (1996) Perisynaptic location of metabotropic glutamate receptors mGluR1 and mGluR5 on dendrites and dendritic spines in the rat hippocampus. Eur J Neurosci 8:1488-1500.

Maccaferri G, McBain CJ (1996) Long-term potentiation in distinct subtypes of hippocampal nonpyramidal neurons. J Neurosci 16:5334-5343.

Maccaferri G, Roberts DBJ, Szucs P, Cottingham CA, Somogyi P (2000) Cell surface domain-specific postsynaptic currents evoked by identified GABAergic neurons in rat hippocampus in vitro. J Physiol (Lond) 524:91-116.

Mannaioni G, Marino MJ, Valenti O, Traynelis SF, Conn PJ (2001) Metabotropic glutamate receptors 1 and 5 differently regulate CA1 pyramidal cell function. J Neurosci 21:5925-5934.

Matsumoto H, Ajmone-Marsan C (1964) Cortical cellular phenomena in experimental epilepsy: interictal manifestations. Exp Neurol 9:286-304.

McBain CJ, Fisahn A (2001) Interneurons unbound. Nat Rev Neurosci 2:11-23.

McBain CJ, Mayer ML (1994) N-methyl-D-aspartic acid receptor structure and function. Physiol Rev 74:723-760.

McLean HA, Rovira C, Ben-Ari Y, Gaiarsa JL (1995) NMDAdependent $\mathrm{GABA}_{\mathrm{A}}$-mediated polysynaptic potentials in the neonatal rat hippocampal CA3 region. Eur J Neurosci 7:1442-1448.

Miles R (1990) Synaptic excitation of inhibitory cells by single CA3 hippocampal pyramidal cells of the guinea-pig in vitro. J Physiol (Lond) 428:61-77.

Miles R, Wong RK (1984) Unitary inhibitory synaptic potentials in the guinea-pig hippocampus in vitro. J Physiol (Lond) 356:97-113.

Mott DD, Lewis DV (1991) Facilitation of the induction of LTP by $\mathrm{GABA}_{\mathrm{B}}$ receptors. Science 252:1718-1720.

Motulsky HJ (1999) How good is the fit? Comparing the fits of two models. San Diego: GraphPad Software Inc.

Neher E (1992) Correction for liquid junction potentials in patch clamp experiments. Methods Enzymol 207:123-131.

Olney JW, Newcomer JW, Farber NB (1999) NMDA receptor hypofunction model of schizophrenia. J Psychiatr Res 33:523-533.

Otmakhova NA, Lisman JE (1999) Dopamine selectively inhibits the direct cortical pathway to the CA1 hippocampal region. J Neurosci 19:1437-1445.

Parra P, Gulyas AI, Miles R (1998) How many subtypes of inhibitory cells in the hippocampus? Neuron 20:983-993

Pouille F, Scanziani M (2001) Enforcement of temporal fidelity in pyramidal cells by somatic feed-forward inhibition. Science 293:1159-1163

Reyes AD, Rubel EW, Spain WJ (1996) In vitro analysis of optimal stimuli for phase-locking and time-delayed modulation of firing in avian nucleus laminaris neurons. J Neurosci 16:993-1007.

Romano C, Sesma MA, McDonald CT, O'Malley K, Van den Pol A, Olney JW (1995) Distribution of metabotropic glutamate receptor mGluR5 immunoreactivity in rat brain. J Comp Neurol 355:455-469.

Sah P, Hestrin S, Nicoll RA (1990) Properties of excitatory postsynaptic currents recorded in vitro from rat hippocampal interneurons. J Physiol (Lond) 430:605-616.

Sayer RJ, Friedlander MJ, Redman SJ (1990) The time course and amplitude of EPSPs evoked at synapses between pairs of CA3/CA1 neurons in the hippocampal slice. J Neurosci 10:826-836.

Schwartzkroin PA (1975) Characteristics of CA1 neurons recorded intracellularly in the hippocampal in vitro slice preparation. Brain Res 85:423-436.

Shadlen MN, Newsome WT (1994) Noise, neuronal codes, and cortical organization. Curr Opin Neurobiol 4:569-579.

Somogyi P, Tamas G, Lujan R, Buhl EH (1998) Salient features of synaptic organisation in the cerebral cortex. Brain Res Brain Res Rev 26:113-135.

Spruston N, Schiller Y, Stuart G, Sakmann B (1995) Activity-dependent action potential invasion and calcium influx into hippocampal CA1 dendrites. Science 268:297-300.

Tsubokawa H, Ross WN (1996) IPSPs modulate spike backpropagation and associated $\left[\mathrm{Ca}^{2+}\right]$ changes in the dendrites of hippocampal CA1 pyramidal neurons. J Neurophysiol 76:2896-2906.

Van Hooft JA, Giuffrida R, Blatow M, Monyer H (2000) Differential expression of group I metabotropic glutamate receptors in functionally distinct hippocampal interneurons. J Neurosci 20:3544-3551.

Vida I, Halasy K, Szinyei C, Somogyi P, Buhl EH (1998) Unitary IPSPs evoked by interneurons at the stratum-radiatum lacunosum-moleculare border in the CA1 area of the hippocampus in vitro. J Physiol (Lond) 506:755-773.

Vinogradova O (1984) Functional organization of the limbic system in the process of registration of information: facts and hypothesis. In: The hippocampus (Isaacson RL, Pribram KH, eds), pp 1-69. New York. Plenum.

Wang XJ (1999) Synaptic basis of cortical persistent activity: the importance of NMDA receptors to working memory. J Neurosci 19:9587-9603.

Watanabe T, Niki H (1985) Hippocampal unit activity and delayed response in the monkey. Brain Res 325:241-254.

Ylinen A, Bragin A, Nadasdy Z, Jando G, Szabo I, Sik A, Buzsaki G (1995) Sharp wave associated high-frequency oscillation $(200 \mathrm{~Hz})$ in the intact hippocampus: network and intracellular mechanisms. J Neurosci $15: 30-46$

Zhang S, Trussel LO (1994) A characterization of excitatory postsynaptic potentials in the avian nucleus magnocellularis. J Neurophysiol 72:705-718. 